\title{
Effect of Winglet Shape on Heat Transfer from Heated Cylinder in Cross Flow
}

\author{
Jalal M. Jalil, Hassan K. Abdulla* and Ahmed H. Yousif* \\ Educational Technology Department, and ${ }^{*}$ Mechanical Engineering \\ Department, University of Technology, Baghdad, Iraq \\ jalalmjalil@yahoo.com
}

\begin{abstract}
Experimental investigation of the flow and heat transfer around a heated cylinder in cross flow with and without using winglets has been carried out. Distribution of the static pressure coefficients and Nusselt number and knowledge of the flow processes around the cylinder without winglets enable as to form an idea of the mechanism and pattern of the flow around the cylinder with winglets. The flow was in fully-developed turbulent flow with Reynolds number range $0.72 * 10^{4} \leq \mathrm{Re} \leq 1.44 * 10^{4}$. Four different shapes of winglets were used with different angles of attack $(20,26,32)$ at different locations $\left(\left(\mathrm{X}_{\mathrm{m}} / \mathrm{D}=0,0.17,0.3,0.5\right),\left(\mathrm{Y}_{\mathrm{m}} / \mathrm{D}=0.57,0.65,0.72\right.\right.$, $0.8)$ ). The results show that there is an effect of winglet shapes on heat transfer and pressure drop, and a better shape is a (trapezoidal (type 3)). For enhanced heat transfer from cylinder, heat transfer increases with increasing Reynolds number and angle of attack. Also the results show that the optimum position of winglet for enhanced heat transfer is $\left(\mathrm{X}_{\mathrm{m}} / \mathrm{D}=0.17\right.$ and $\left.\mathrm{Y}_{\mathrm{m}} / \mathrm{D}=0.65\right)$. The research shows that heat transfer is enhanced as high as $(14 \%)$ when winglets are used when compared with the case of a cylinder without winglets. There is also a slight increase in pressure drop.
\end{abstract}

Keywords: Heat transfer, Enhancement, Winglet.

\section{Introduction}

Investigation of flow and heat transfer over a cylinder in cross flow is very important due to its wide use in engineering practices and to insufficiently investigated effects of particular geometrical parameters on the flow processe ${ }^{[1]}$. The flow over cylinder is a complicated flow with a large number of parameters involved ${ }^{[2]}$. Also, there does not seem to be studies carried out concerning the features of heat transfer from cylinders by using winglets, although there are studies for enhancement in heat transfer from fin-tube heat exchanger with wings and winglets as in Ref.[3]. The latter study investigates enhancement in heat transfer from a 
fin tube heat exchanger with winglets by disrupting the growth of thermal boundary layer and reducing the minimum surface heat transfer in the wake region directly down stream of circular tubes. In channel flow without cylinder, many works have been published using vortex generator to enhance heat transfer ${ }^{[4-6]}$.

Flow around circular cylinders and boundary layer separation have been investigated experimentally as in Ref. $[1,7,8]$ and numerically as in Ref. $[9,10,11]$. These studies show that the variation in the local Nusselt number $(\mathrm{Nu})$ around the cylinder is effected by the boundary layer development in the front of the cylinder and by separation and vortex shedding over the side and the wake region. The maximum heat transfer occurs at the front stagnation point where the boundary layer resistance to heat transfer is minimum. The minimum heat transfer is found to correspond to the point before the boundary layer separates and the location of the minimum heat transfer depends on the Reynolds number of the flow. It should be noted that no study was found, to the best knowledge of the authors, which aimed to investigate fluid flow and heat transfer over a cylinder by using winglets. The local heat flux in the front region of the cylinder (up to $50^{\circ}$ ) is relatively high, after this point the local heat flux decreases until the separation point (minimum Nusselt number) then heat transfer will be approximately constant and nearly equal to that at separation point ${ }^{[1]}$. This work will concentrate on altering wake region so as to seek for possibilities for enhancing heat transfer from cylinder. The strategy of this work is to place winglets behind the cylinder (Fig. 1) to control flow over the cylinder surface. Four shapes of winglets were used in this investigation as shown in Fig. 2, the winglets have the same height and area.

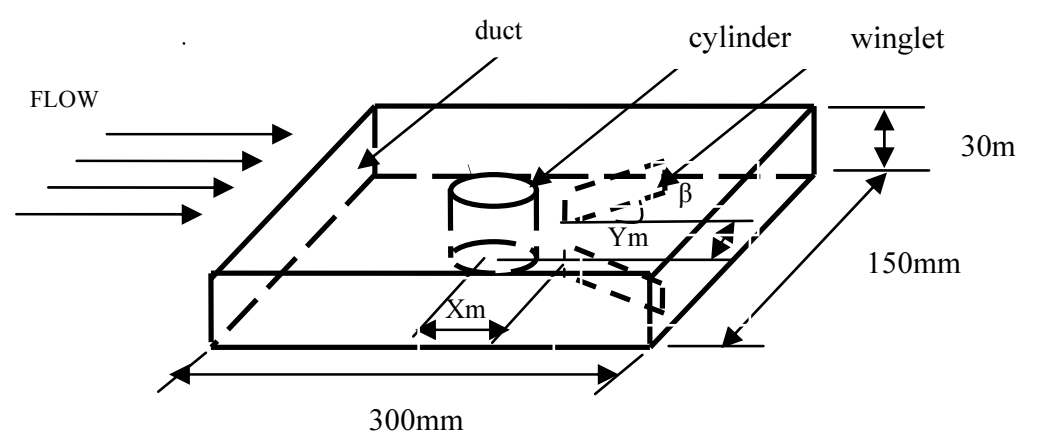

Fig. 1. Test section. 


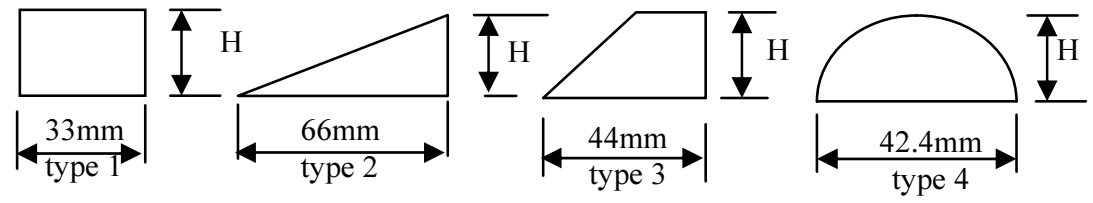

Fig. 2. Schematic view of winglets.

\section{Experimental Procedure}

The aim of this part of the study was to investigate the influence of the winglet on fluid flow and heat transfer over a cylinder experimentally. The calculation of Nusselt number and pressure distribution over the cylinder surface was in turbulent flow with different positions, angle of attack and Reynolds number at constant heat flux.

By using the apparatus shown in Fig. 3, the pressure difference and temperatures on the cylinder surface can be measured. This apparatus contains a long narrow rectangular duct $30 * 150 \mathrm{~mm}^{2}$ in cross section, the length of duct being $2000 \mathrm{~mm}$ to obtain fully developed flow, and a $30 * 150 * 300 \mathrm{~mm}^{3}$ test section containing the $55 \mathrm{~mm}$ diameter cylinder in the middle of the test section. This cylinder was heated by using electric resistance to obtain a constant heat flux, whereby the current and voltage drops were measured with electric multi-meter, and by using a variac to obtain the desired heat flux. A pitot-static tube was used for measuring velocity of flow and the pressure drop across test section, the temperatures of fluid at inlet and outlet from the test section were measured by using four thermocouples. By using a fan with manual control, the flow entering the duct can be obtained. The winglet consisted of small plates mounted behind the center of the cylinder as shown in Fig.1.

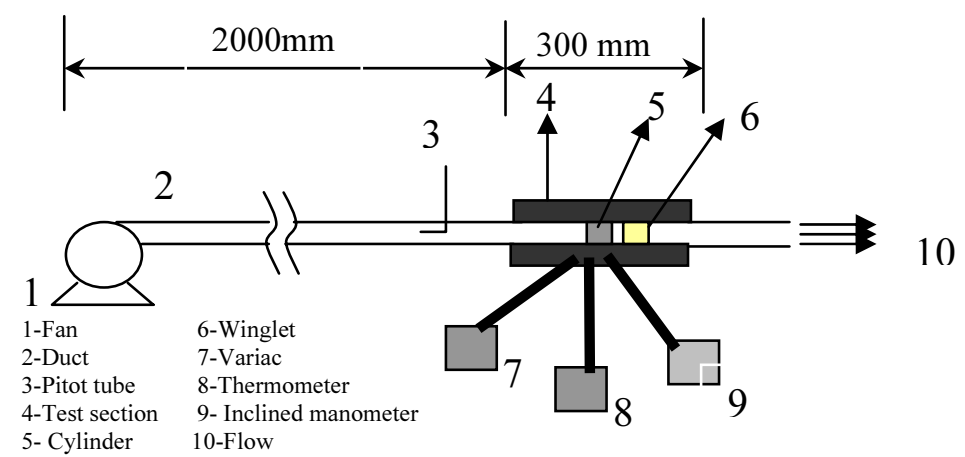

Fig. 3. Schematic view of experimental apparatus. 


\subsection{Pressure Distribution}

Pressure distribution on the cylinder surface can be obtained by using five holes with $45^{\circ}$ between the neighboring holes, the holes being connected to an inclined alcohol manometer through pressure taps joined with the holes from the bottom surface of the cylinder to prevent any disruption of the flow over the cylinder. The following dimensionless form definition was used to calculate the pressure coefficient.

$$
c p_{\Theta}=\frac{p_{\Theta}-p_{\mathrm{O}}}{0.5 * \rho^{*} u_{a v}^{2}}
$$

\subsection{Heat Transfer Distribution}

Heat transfer distribution on the cylinder was measured by using five thermocouples of type $(\mathrm{k})$ joined to the bottom surface of cylinder to prevent any disruption of the flow over the cylinder. The thermocouples were connected with an electro-thermometer through a selector switch, the thermocouples being connected with $45^{\circ}$ between neighboring thermocouples. By using the following relations, heat transfer distribution on cylinder can be obtained

$$
\begin{aligned}
& N u_{\Theta}=\frac{h_{\Theta} * H}{k} \ldots \ldots \ldots . . . \\
& \text { where } \ldots h_{\Theta}=\frac{Q}{A^{*} \Delta T} \\
& Q=I^{*} V \ldots \ldots \ldots \ldots \ldots \\
& A=\pi^{*} D^{*} H \ldots \ldots \ldots \\
& \Delta T=\left(T_{\Theta}-T_{b}\right) \ldots \ldots \ldots \\
& T_{b}=\frac{T_{\text {in }}-T_{\text {out }}}{2} \ldots \ldots \ldots \ldots
\end{aligned}
$$

All fluid properties were taken at the arithmetic mean for the bulk temperature.

Reynolds number can be calculated from

$$
\operatorname{Re}=\frac{u_{a v} * H}{v}
$$




\section{Results and Discussion}

Figure 4 shows the local heat transfer and local pressure coefficient for flow over the cylinder with rectangular winglet (type 1) at $\left\{\mathrm{Re}=1.08 * 10^{4}, \mathrm{Xm} / \mathrm{D}=0.17, \mathrm{Ym} / \mathrm{D}=0.65, \beta=26^{\circ}\right.$ and different longitudinal distances along the streamline $(\mathrm{Xm} / \mathrm{D})\}$ and without winglet (free). For the free case, the local heat transfer is observed to be largest at the front stagnation point. Then it decreases due to increasing boundary layer thickness, and reaches its minimum value at the separation point. It then increases because considerable turbulent exists over the rear side of cylinder, where eddies of the wake sweep the surface. The heat transfer over the rear is not higher than at the front because the eddies recirculate part of heated fluid.
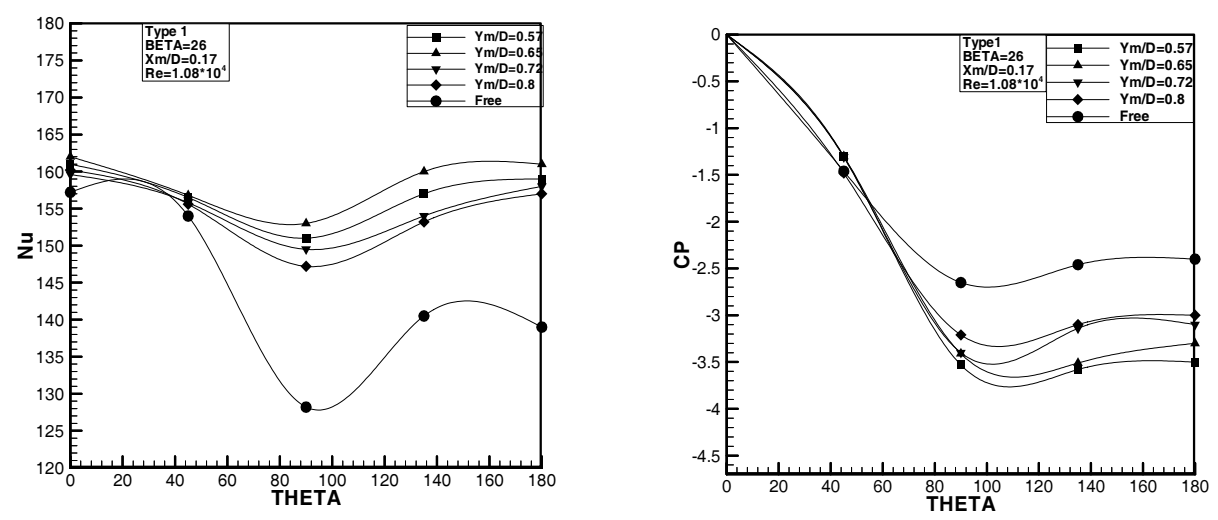

Fig. 4. Effect of $\mathrm{Xm}$ on $\mathrm{Nu}$ and $\mathrm{Cp}$ for type 1 at $\mathrm{Re}=1.08 * 10^{4}, \mathrm{Ym} / \mathrm{D}=0.65, \beta=26$.

Also, it may be observed in the same figure that local heat transfer is increased by using the winglet, and that the value of the local heat transfer is dependent on the position of the winglet. The optimum value of heat transfer occurs at $(\mathrm{Xm} / \mathrm{D}=0.17)$, where in the case of small distance $(\mathrm{Xm} / \mathrm{D}<0.17)$ there is a narrowing gap between the cylinder and the winglet and not enough heat will be removing from the cylinder. In the case of a large gap $(\mathrm{Xm} / \mathrm{D}>0.17)$ the effect of the winglet will be decreasing. For the case of flow without using the winglet, the local pressure coefficient will be increasing with increasing distance from the stagnation point due to acceleration of the flow around the cylinder. At about $90^{\circ}$ the pressure becomes minimum and separation will occur, but when using the winglet the pressure coefficient will be decreasing due to 
the acceleration of the flow through the narrow gap between the cylinder and the winglet.

Figure 5 shows variation of the local heat transfer and the local pressure coefficient for flow over the cylinder with a rectangular winglet (type 1) at $\left\{\mathrm{Re}=1.08^{*} 10^{4}, \mathrm{Xm} / \mathrm{D}=0.17, \mathrm{Ym} / \mathrm{D}=0.65, \beta=26\right.$ and different transfer distances $\mathrm{Ym} / \mathrm{D}\}$ and for the case when a winglet is not used (free). The local heat transfer is observed to increase when using the winglet as mentioned above, the optimum position for high heat transfer being at $(\mathrm{Ym} / \mathrm{D}=0.65)$. For lower values $(\mathrm{Ym} / \mathrm{D}<0.65)$, the heat transfer will be lower because the flow moves away due to the small gap between the cylinder and the winglet. When the distance is $(\mathrm{Ym} / \mathrm{D}>0.65)$, heat transfer will be reduced and the effect of winglet will be decreased because the gap becomes large. Local pressure coefficient will be increasing when using the winglet as mentioned above. For the other types of winglets, the same type of results may be shown to occur, but at different values, depending on the type of winglet.
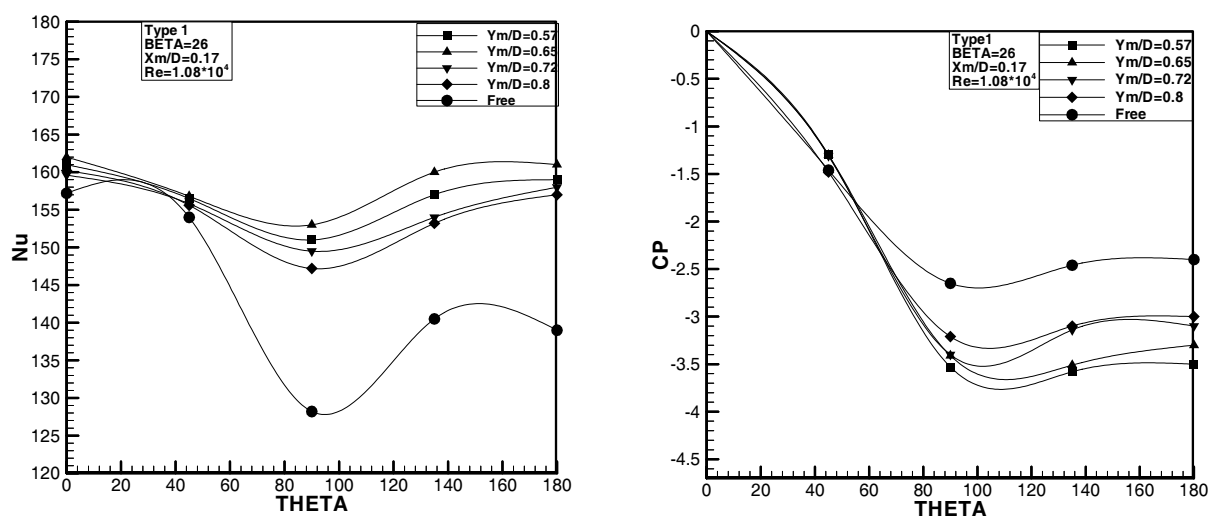

Fig. 5. Effect of $\mathrm{Ym}$ on $\mathrm{Nu}$ and $\mathrm{Cp}$ for type 1 at $\mathrm{Re}=1.08 * 10^{4}, \mathrm{Xm} / \mathrm{D}=0.17, \beta=26$

Figure 6 shows the influence of the angle of attack on local heat transfer and pressure coefficient for rectangular shape at $\left(\operatorname{Re}=1.08 * 10^{4}\right.$, $\mathrm{Xm} / \mathrm{D}=0.17$ and $\mathrm{Ym} / \mathrm{D}=0.65$ ). It may be observed that heat transfer increases with increasing angle of attack. This is because of increasing pressure difference across the winglet faces and the increasing fluid passing through the gap between the cylinder and the winglet and removing of more heat from the cylinder. Also, the same procedure can be shown for other winglet shapes. 
Figure 7 shows the local pressure drop around the cylinder when using a rectangular winglet. It is observed that local pressure falls as flow is accelerated with increasing angle of attack. The same process can be shown to arise when other winglet shapes are utilized.

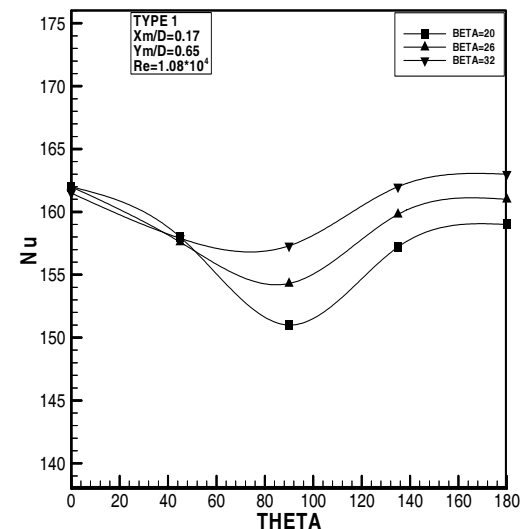

Fig. 6. The influence of angle of attack on pressure coefficient.

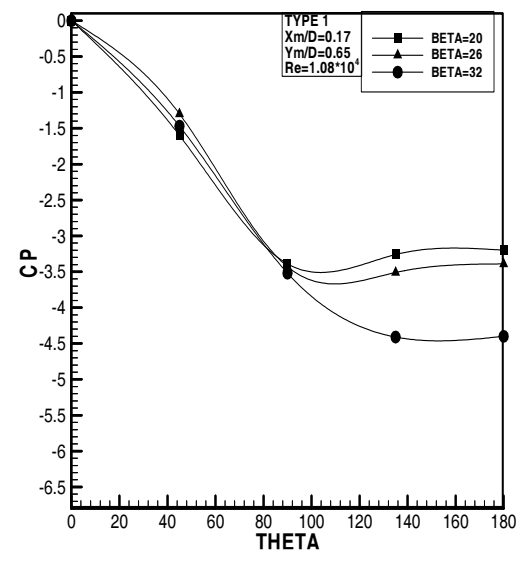

Fig. 7. The influence of angle of attack on heat transfer for rectangular shape.

Figure 8 shows the comparison of heat transfer when all types of winglets are used and with the case of no winglet at $\left(\mathrm{Re}=1.08^{*} 10^{4}\right.$, $\mathrm{Xm} / \mathrm{D}=0.17, \mathrm{Ym} / \mathrm{d}=0.65$ and $\beta=26$ ). It may be concluded that heat transfer with all types of winglets is more than the case of using no winglet.

Additionally, the figure shows that the trapezoidal winglet (type 3) yields the best results, i.e., it is the best shape for enhancing heat transfer. This is due to the significant effect on acceleration of the flow when passing across the sharp edge of the trapezoidal winglet. Consequently no flow recirculation arises as in the rectangular winglet (type 1) or elliptical winglet (type 4) due to the narrow gap. The triangular winglet (type 2) provides the minimum heat transfer when compared to other types due to the small effect for accelerating the flow to pass near the cylinder and some of the flow passes over the winglet. 


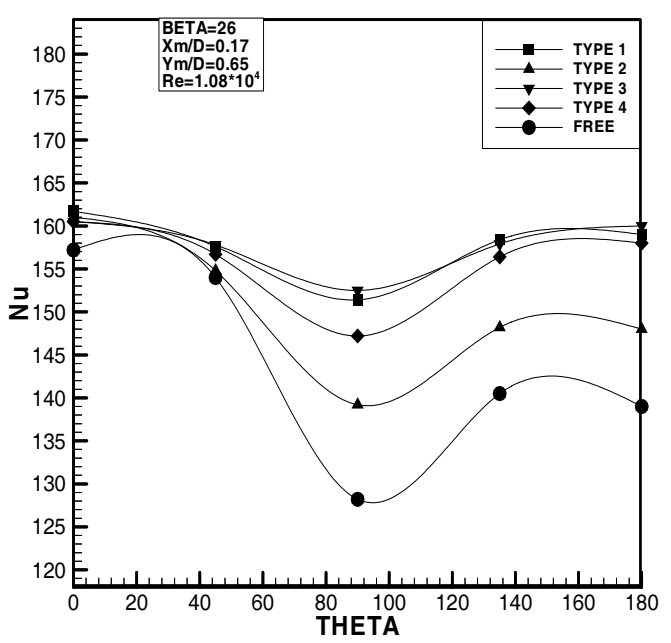

Fig. 8. Comparison of local heat transfer for all types of winglets.

Figure 9 shows the distribution of pressure coefficient at $\mathrm{Xm} / \mathrm{D}=$ $0.17, \mathrm{Ym} / \mathrm{d}=0.65$ and $\beta=26)$. It may be observed that the pressure falls when using winglet types (1) and (2), where the pressure drop is high due to high pressure difference across the winglet faces.

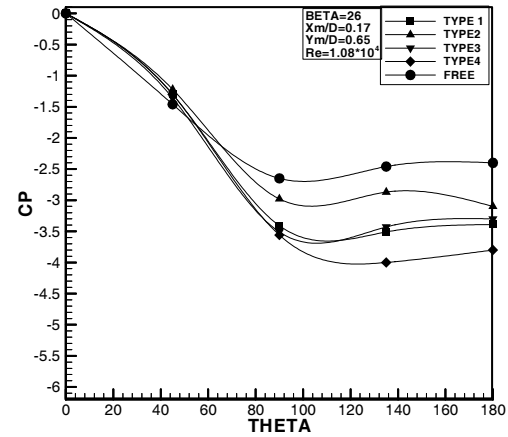

Fig. 9. Comparison of local pressure coefficient.

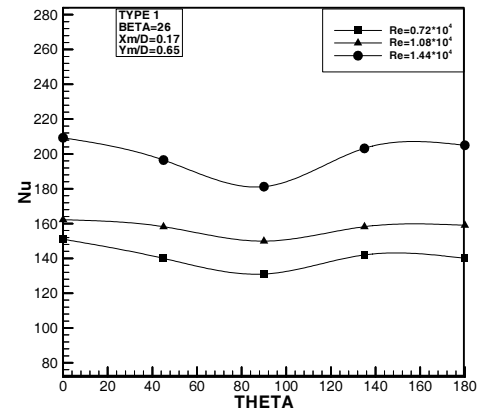

Fig. 10. Effect of Reynolds number on local heat transfer for rectangular shape.

Figure 10 shows the effect of Reynolds number on heat transfer at $(\mathrm{Xm} / \mathrm{D}=0.17, \mathrm{Ym} / \mathrm{D}=0.65, \beta=26)$ for the rectangular winglet. The results indicate that heat transfer increases with increasing $(\mathrm{Re})$ due to acceleration of the flow over the surface of the cylinder.

Figure 11 shows the effect of $(\mathrm{Re})$ on $(\mathrm{Cp})$ for the rectangular shape at $\mathrm{Xm} / \mathrm{D}=0.17, \mathrm{Ym} / \mathrm{d}=0.65$ and $\beta=26$ ). As expected, the pressure drop increases with increasing $(\mathrm{Re})$ due to accelerated flow around the cylinder surface. 
For all above figures heat transfer and pressure drop over the front face of cylinder are relatively constant due to accelerating flow and the resulting thinner boundary layer. The effect of winglets is felt on the rear face of the cylinder.

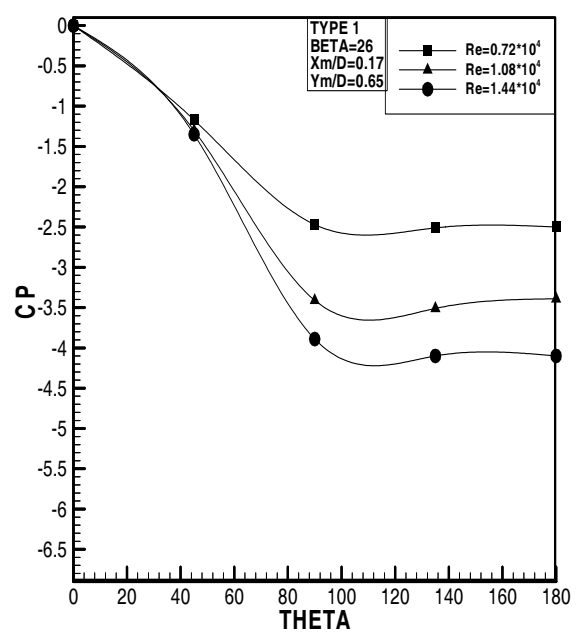

Fig. 11. Effect of Reynolds number on local pressure coefficient for rectangular shape.

\section{Conclusion}

The most important results can be summarized as follows:

- Winglets accelerate the flow to sweep the heat from high heated region on cylinder surface.

- Heat transfer is enhanced by about $(14 \%)$. Pressure drop is increased only slightly.

- Heat transfer increases with increasing angle of attack.

- Heat transfer increases with increasing Reynolds number.

- The position of winglets $(\mathrm{Xm} / \mathrm{D}, \mathrm{Ym} / \mathrm{D})$ is very important, and it effects heat transfer.

- The maximum heat transfer occurs at (approximately) $\mathrm{Xm} / \mathrm{D}=0.17$ and $\mathrm{Ym} / \mathrm{D}=0.65$

- The trapezoidal winglet is the optimum type for enhanced heat transfer. 


\title{
Notations
}

\author{
$\mathrm{A}=$ Area \\ $\mathrm{Cp}=$ Static pressure coefficient \\ $\mathrm{D}=$ Diameter of cylinder \\ $\mathrm{H}=$ Duct height and winglets \\ $\mathrm{h}=$ Local heat transfer coefficient \\ $\mathrm{I}=$ Electric current \\ $\mathrm{K}=$ Thermal conductivity \\ $\mathrm{L}=$ Length of cylinder \\ $\mathrm{Nu}_{\theta}=$ Local Nusselt number \\ $\mathrm{P}_{\mathrm{o}}=$ Stagnation pressure \\ $\mathrm{P}_{\theta}=$ Local pressure \\ $\mathrm{Q}=$ Total heat transfer \\ $\mathrm{Re}_{\mathrm{H}}=$ Reynolds number at duct height \\ $\mathrm{T}_{\mathrm{a}}=$ Air temperature \\ $\mathrm{T}_{\text {in }}=$ Inlet temperature \\ $\mathrm{T}_{\text {out }}=$ Outlet temperature \\ $\Delta \mathrm{T}=$ Temperature difference \\ $\mathrm{u}=$ Inlet velocity \\ $\mathrm{V}=$ Volt \\ $\mathrm{X}_{\mathrm{m}}=$ Longitudinal distance from cylinder center \\ $\mathrm{Y}_{\mathrm{m}}=$ Transverse distance from cylinder center \\ $\rho=$ Density \\ $v=$ Dynamic viscosity \\ $\beta=$ angle of attack
}

\section{References}

[1] Kostic, Z. G. and Oka, S. N., "Fluid flow and heat transfer with two cylinders in cross flow", Int. J. Heat Mass Transfer, 15, 279-299,1972

[2] Ertan, B., " Heat transfer and flow structures around circular cylinder in cross flow ", Tr. J. of Engineering and Environmental Science, 23: 299-315(1999).

[3] Tiwari, S., Prasad, P.L. and Biswas, G., "A numerical study of heat transfer in fin tube heat exchanger using winglet type vortex generator in common-flow down configuration ", Progress in Computational Fluid Dynamic, 3(1) (2003).

[4] Fiebig, M., Kallweit P., Mitra, N.K. and Tigglebeck, S., "Heat transfer enhancement and drag by longitudinal vortex generators in channel flow., Int. J. Exp. Therm. Fluid Sci., 4 (1) (1991).

[5] Tigglebeck, S. Mitra, N.K. and Fiebig, M., "Comparison of wing type vortex generators for heat transfer enhancement in channel flows" Trans. ASME, J. Heat Transfer, 116(3-4) (1994). 
[6] Torii, K., Subbarao, P.M.V. and Biswas, G., "Experimental study on enhancement of heat transfer due to the longitudinal vortices in a channel flow", Proceedings of Third ISHMT-ASME Heat and Mass Transfer Conf., DT Kanpur, India (1997).

[7] Achenbach, E., " Total and local heat transfer from smooth circular cylinder in cross flow at high Reynolds number “Int. J. Heat Mass Transfer, 18: 1387-1395 (1975).

[8] Figueiredo, A.R. and Viegas, D.X., "External force convection around circular cylinder near a plan boundary “, Int. J. Heat Mass Transfer, 31(1): 47-52 (1988).

[9] Karniadatis, G.E., "Numerical simulation of force convection heat transfer from cylinder in cross flow “, Int. J. Heat Mass Transfer, 31: 107-118 (1988).

[10] Chon, W. and Boch, R. F., "Calculation of force flow and heat transfer around cylinder in cross flow “, Numerical Heat Transfer, 15: 101 -122 (1989).

[11] Kurdyumar, V. N. and Fornamdes, E., "Heat transfer from circular cylinder at low Reynolds number “, ASME, 120: $72-75$ (1998). 


\section{تأثير شكل مولا الاوامات على انتقال الحرارة من أسطو انة مسخنة}

جلال محمد جليل، وحسن كريم عبد الله" ، وأحمد هاثم يوسف"

قسم التعليم التكنولوجي، الجامعة التكنولوجية،

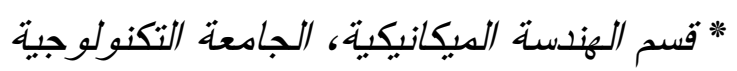

$$
\text { بغد/د- العراق }
$$

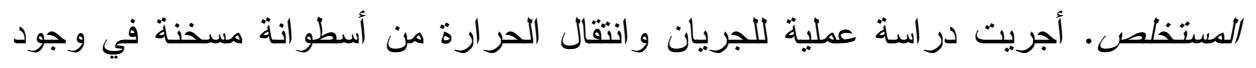

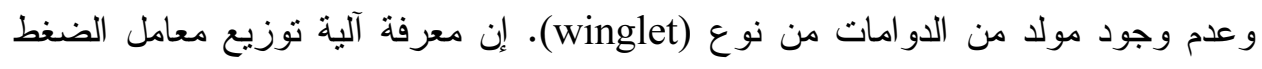
السكوني ورقم نسلت للجريان حول الأسطوانة بدون استخدام مولد الدوامات (winglet)

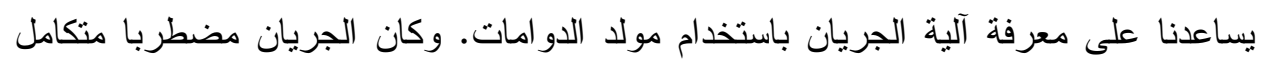

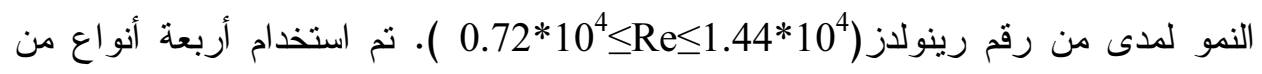

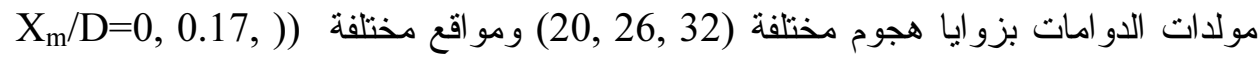

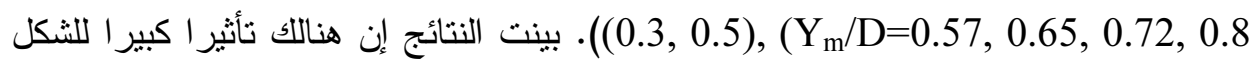

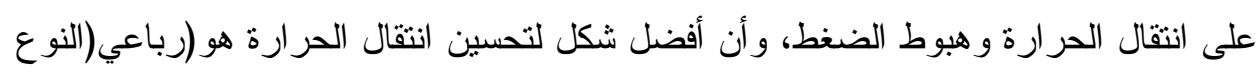

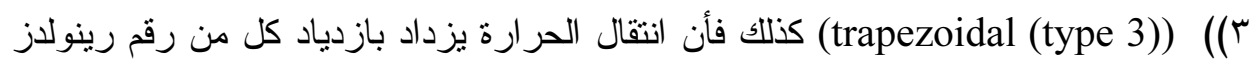

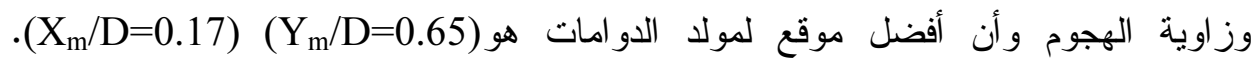

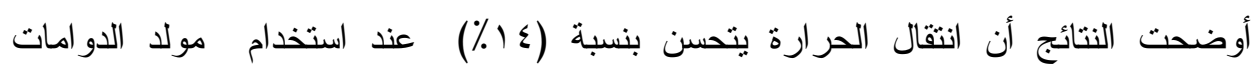

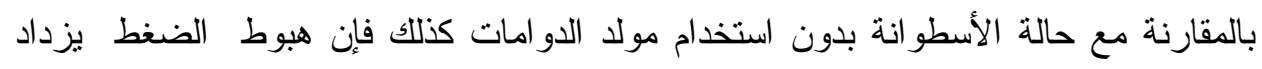
بشكل بسيط. 